\title{
Glaring invisibility: dressing the body of the female cleaner
}

\author{
Maheshvari Naidu \\ School of Anthropology, Gender and Historical Studies, University of KwaZulu Natal, \\ Private Bag X5400I, Durban, 400I, KwaZulu-Natal \\ naiduu@ukzn.ac.za
}

\begin{abstract}
The paper explores how the uniform of a group of female cleaners appears to be more than an abstract object framed by the practical exegetics of work. The uniform is seen as acting as a material exercise of discretionary and disciplinary power of inscription, and as the paper shows, emerges as a mode by which the cleaners are homogenously objectified and plastically turned into 'subjects' (Foucault 1982). The paper shows too that while the single layered cleaners' uniform can be seen as disciplining the body and stripping down the complex multi-layers of their personality and attempting to naturalise their status as cleaners, the women's narratives reveal their attempts to destabilise this conscription, if only outside the spatial and organisational domain of the work space.
\end{abstract}

Key Words: Body, uniform, plasticity, inscription, discipline, docile, narratives

\section{Introduction: Why study uniforms?}

This paper' uses data gathered through observation and interviews to explore how the uniform or 'dress' of a group of female cleaners appears to act as more than an abstract object framed by the practical exegetics of work. The study is refracted through the theoretical notion of 'plasticity' (Grosz 1987; Bordo 1993), which argues that in a sense the body can be molded, formed and organised. The notion of plasticity is particularly exciting as it allows an understanding that bodies are 'sites' that can be molded and shaped by particular hegemonic discourses. 'Plasticity' is understood, not in a material sense of reshaping or adorning bodies vulnerable to hegemonic discourses of beauty, but rather as referring to the malleable body being shaped with appropriate sets of behaviours (Grosz 1987).

The paper attempts to show that a uniform inscribes particular scripts onto the bodies of women who wear them daily in the workplace, inscribing and disciplining (Foucault 1977) who they are at work. The uniform is seen as acting as a material exercise of discretionary and disciplinary power of inscription, and, as the paper shows, emerges as a mode by which the cleaners are turned into 'subjects' (Foucault 1982).

While only a segment of the population will ever wear a uniform as such, various forms of dress are worn daily on the body almost as a form of practice. Rafaeli and Pratt (1993: 33; see also Appadurai 1986) assert that the consensus in the literature is that bodily clothing is able to communicate symbolically, messages that are at once strong and powerful, to both the wearer and the observer. The catalyst for this paper was the observation by a female student that cleaners daily and routinely arrive at the University by buses and taxis dressed in their full casual day wear. The next time staff and students have the occasion to see the women, they have donned the standard uniform of blue and green button-down dress and apron ensemble, which they then wear for the next eight and half hours, until the end of the work day. It was intriguing to explore whether the women experienced themselves as substantially different while wearing the uniform at work, and how they experienced the actual wearing of the uniform.

And while we may not be the ones in uniform, almost on a daily level, in the context of the work space, and often in the confines of our home space, women (and men) move around us in particular uniforms, cleaning those self same spaces. An understanding of how particular subordinate groups, doing relatively low paid work, may have their experiences of themselves inscribed by what they are obligated to wear, contributes to a capillary level understanding of how particular codes of behaviour come to be 'worn' on bodies rendered docile (Foucault 1977).

This kind of research is potentially valuable as it is through the "force of production" that the body comes to be invested "with relations of power and domination" (Foucault 2006: 354). The body is a site of social control and the uniform is construed as a means by which such relations of power and disciplinary control come to be exercised and experienced. Foucault himself claimed in one of his essays that it was not his aim to analyse what he terms the phenomenon of power, but rather how people are turned into subjects, and that his goal was "to create a history of the different modes" by which "human beings are made subjects" (Foucault 1982: 777). The uniform is understood in the context of the study as one means by which women are disciplined and objectified into subjects. The narratives of the women's experiences are viewed as texts for gaining a window into the disciplining of women's bodies through inscription, showing through ethnographic snapshots how the 'dress comes to wear the women'(my emphasis).

The claim is that labour is very much a material, bodily practice where bodies are (discretionarily and coercively) organised, deployed and consumed. Organisational culture, as would be relevant in a university as an example of an organisation, is often the context in which the meaning of a

I. I would like to acknowledge the two anonymous reviewers for their meticulous and critical reading of the paper and the invaluable insights and comments that they offered. 
symbol, in this instance, the meaning of the uniform-dress, is 'enacted', because 'culture' acts to define the shared frame of reference that typifies organisations and guides organisational behaviour (Messing 1998).

The first part of the paper contextualises the theoretical perspective around 'body' and cleaning work, and outlines in detail the particular methodological approach, while narratives from the interviews and observations are presented in the second part of the paper. The element of lived experience remains as a focus of analysis as we approach the issues around the seemingly simple 'dress' or uniform by listening to the women 'tell' about their experiences wearing it. These shared experiences allow a probing around the women as socially defined, publicly visible beings. The paper also probes whether there is a level of subversion on the part of the women against what the uniform may be doing to both their bodies, and their perceived social selves.

\section{The female body and cleaning work}

According to Connell (1994: I I), the earlier feminist theorists such as Rosaldo and Lamphere and Rayna Reiter saw the division of labour as central to the subordination of women. There has additionally always seemingly been low prestige and value attributed to woman's work, particularly cleaning work. This traces back to the origins of 'cleaning' as part of women's work at home and its association with nonproductive (unpaid) labour. And within domestic tasks, cleaning is positioned at the bottom of the list (Messing 1998: 178, 179). While some may not see continuity between the domains of private and public in this context, Lan (2003: 188) brokers a theoretical meeting of the two domains by viewing unpaid household labour and paid domestic work as structural continuities across the public and private spheres. This structural continuity makes material sense to me, for in the context of this paper, cleaners, as members of a subcontracted company at the University may be perceived as 'doing domestic' work. They clean, dust, wash, mop, polish, vacuum, empty bins, and operate machines in some instances, to get the (cleaning) work done.

Writing in the South African journal Agenda more than a decade ago, during a time when South Africa could rightly be presumed to be an infant democracy, Grant (1997: 62) drew attention to the then operating ideological framework for domestic labour within the country, claiming that South African society had historically attached a low premium to both the categories of women's work and to that of black labour in general. Domestic work especially, was perceived as particularly undervalued because it had traditionally been treated as women's unpaid duty in marriage which then extended outside of marriage when many 'unskilled' women entered the workforce and were obliged to take on cleaning work in private homes and organisational institutions, schools, universities, factories, and indeed the nook and crannies of many economic institutions, all of which needed the services of cleaners. Grant goes on to say that many black women found themselves in the position where they were obliged to perform underpaid, undervalued (women's) work, and return home to do exactly that women's work again as wives and partners, sometimes also undervalued, and in this context, also unpaid.
The uniform as an artefact and symbol of obligatory organisational dress is certainly not limited to categories of only female cleaning staff, even at the University. However, it is with the peculiar behavioural proscriptions associated with the uniform of the female cleaning staff that the paper is concerned. Formal dress (unlike that of the staff at an outlet such as McDonald's) such as the uniforms worn by bank workers, pharmacy assistants etc. is associated either directly or indirectly with the category of 'professional' even if the wellness might not represent a 'professional' organisation, alluding perhaps merely to the 'uniqueness' (Rafaeli \& Pratt 1993: 38) of dress attributes in a particular organisation in comparison with dress outside the organisation. However, there is nothing unique about the dress of the cleaners, which is very similar in design to the dress of other cleaners at other universities or at companies that employ cleaners, and indeed as stressed in the narratives of the women, it is a source of immediate association with cleaning work.

\section{Methodological approach}

Anthropology privileges 'face to face encounters' and indeed, as clichéd as it might well sound, ethnography is still touted as the hallmark of the anthropological approach in the social sciences. While life is full of (very) naturally occurring (multiple) face-to-face encounters, ethnography is the conscious seeking out and documenting of such encounters (which we might well not otherwise have done) as part of a disciplinary methodological praxis where social scientists attempt to probe and analyse and further refract these encounters through particular theoretical lenses in order to better understand people, and the worldviews people construct and inhabit. In a space such as a dynamic tertiary learning institution or a university, there are necessarily multiple categories of women, inhabiting dramatically different social fields within the same space. The female cleaners are one such category. There are of course male cleaners on the campuses and members of the same contracted cleaning company as the women, who work primarily cleaning the male toilets and large lecturing spaces. The study chooses though, to narrow its focus on the experiences of the uniformed cleaning women.

While there are also notably, a smaller number of Indian women who work as cleaners on the sister Westville campus, the informants in this paper are all black African. The African women were predominantly, although not exclusively, from Zulu-speaking traditions in the age group spanning 30-52 years. While some were married, others lived with their partners or headed single households. This 'filtering' was conscious as it was felt that, while the Indian cleaners might have echoes and similarities with the experiences of their African co-workers, a narrower microsociological gaze on African cleaners allow us to hear stories that might well be discrete to particular sociocultural realities of African women. Within the context of South Africa's historical trajectory, many black women find themselves in a position where they are obliged to perform the only work available, which is usually some permutation of cleaning work. It was noted that the African women in the study traveled far, often taking more than one mode of transport to get to work. In many instances, these women had to get their school-going children ready before setting off for work. The contracted cleaning companies also 
largely recruited African women. The Indian cleaners were older women who had entered contracts many years ago. They were therefore mostly elderly women with older or grown children who required little or no assistance in the mornings.

Thus, while it may well have appeared a methodological faux pax to have excluded the Indian cleaners for the sample community, but include women other than Zulu-speaking, this particular filtering process was regarded as justified. Many of the non-Zulu-speaking women were comfortable associating and conversing with their Zulu-speaking co-workers. While this was not necessarily untrue for the smaller group of Indian workers, their relatively smaller numbers and presence predominantly on one campus were also points for consideration. Another consideration (for some aspects of the interviews) was that the African women were more familiar with domestic work because some of them had either been employed as domestic workers, or had friends or acquaintances who were currently employed as domestic workers. The same could not be said for the Indian cleaners. And while is not presumed that all black African women, or even all black Zulu-speaking women have the same experiences and cultural views, it is assumed, that the black Indian women have cultural views that would be relatively more dissimilar. The sampling thus sought to focus on one so-called grouping of women, with an awareness that a diversity of experiences might also surface within this singular grouping.

It was relatively easy (from the University's website, and communications with the Department of Human Resources and Information Management) to obtain figures on the number of female academics or female administrators, and the racial demography of these categories of women. However, it was impossible to obtain the same information on the number of female cleaners employed at each campus, or on their racial profile. There appeared to be intense organisational anxieties, from the offices of the University as well as the managers of the contracted cleaning companies in response to my requesting this type of information. Information sessions on what I was attempting to research were met with guarded suspicion, and although a formal response was promised, none was forthcoming. I mention this, since this kind of organisational response undergirds the premise that cleaning work and cleaners are not construed as significantly important to be studied, except for reasons pertaining to what Management viewed as incendiary issues cohering around employees' pay and work conditions.

Given all of this, my methodological entry was somewhat clandestine and my immediate entrée was an informant known to me as the person who regularly cleaned the offices of the building in which I work, and who was fortuitously able to introduce me to other women. These women in turn, pointed me to other women working in neighbouring buildings on the Howard campus or on one of the two sister campuses, Westville and Edgewood. A research assistant was used for some of the one-on-one interviews, but not for the focus groups and interviews involving multiple meetings and encounters. Some of the Indian cleaners were known to me as the 'aunties' who had cleaned my, and colleagues' offices over the ten-year period that I have worked on the Westville campus. These women were able to introduce me to their black African co-workers. This snowball method thus proved highly fruitful in meeting many of the research participants whom I interviewed, mainly during their lunch breaks.

'Conversations as interviews' were conducted with fiftyfive women across three sister campuses of the University of KwaZulu-Natal. Since the women also wished to remain anonymous in the study, I have chosen to use pseudonyms ${ }^{2}$ when I refer to the telling of their experiences. Some of the women were interviewed individually. Others were interviewed in small focus groups of three or four when it became clear that this would make them more comfortable. All were fairly at ease in English although there were often instances during the focus groups where one woman would ask that her ideas, expressed in her native tongue, be translated by the co-worker seated next to her. More sustained contact and multiple encounters were held with a small group of approximately twelve women over a four month period in the first half of 2009. While stock questions were posed to all the women, 'conversation' was a powerful means of gathering stories, and allowed a natural surfacing of issues that unveiled the complex materiality of the women's lives.

While no issues were suppressed in any way, this paper is necessarily circumscribed to probe how the dress is experienced as embodied practice and sensibility, and how at the material and experiential level, the women experienced themselves while wearing the dress-uniform. Thus issues of conspicuousness and invisibility in relation to the uniform were circumscribed as focal enquiries. As such all issues dealing with their anxieties over salaried status and the recent exchanges between the cleaners' union representatives and management lie outside this paper.

\section{Constructing visible (ugly?) bodies}

In the context of this study, the 'dress' is a work(ers') uniform designed as a simple blue button-down dress with green trimmings and an apron worn over it. An accompanying headscarf completes the outfit. Karen Messing's (1998) study looks at how organisational dress operates as a mechanism for asserting organisational control within the context of a hospital environment, showing that control often undergirds issues of dress. Deborah Durham's (1999) article examines what she refers to as the contents of Herero dress-consciousness, claiming that the meaning of this dress carries the imprint of 'relations of domination'. While both Durham's work and Messing's studies are important works that draw attention to a garment that is overlaid with complex concerns of female body construction and relations of domination, it is the latter's study, situated as it is within a particular category of cleaning women, that is of direct interest in this paper.

One of the themes explored in Messing's (1998) article was that of 'visibility' and in her view, all the female hospital cleaners in her study experienced themselves as invisible in relation to the rest of the hierachied staff in the hospital. The women's experiences revealed that, both their work in the

2. As the research participants all wished to remain anonymous, I place an asterisk* after their names as a reminder that the names used in the paper, are pseudonyms. 
hospital as well as they themselves as cleaners (my emphasis), were cloaked and invisible to the staff, patients and visitors with whom they came into contact. This was echoed in their utterance to Messing, "we don't exist for them, and we are invisible" (my emphasis) (Messing 1998). In several instances the stories revealed that the cleaners were forbidden to talk with patients. Invisibility of cleaners was also reinforced by the fact that the cleaners were meant to organise their work so as not to interfere with other personnel and their work (Messing 1998: 173, 175).

I was keen to investigate this notion of invisibility among the cleaners at the various campuses. It was my assumption that they would experience a certain level of invisibility surrounded as they were by other young women and men who were noticeably better positioned than they were, both economically and because of the levels of education they were able to access. However, the narratives of the women revealed it was less a matter of experiencing a sense of invisibility, but rather the opposite, viz. that of heightened visibility or conspicuousness. As comments from staff and students also indicated, it appeared to be a matter of being too visible or hypervisible.

While the Herero dress may well, as Durham (1999: 391) states, be a 'shifty signifier' for the Herero, in the sense of revealing the slipperiness of their ethnic identities, for the participants in this study, dress works as a kind of static and 'locked' signifier of hypervisibility, pointing out unambiguously, who the women are at work. Conspicuousness of dress refers to the extent to which the dress or uniform of organisation members stands out from the dress of non-members (Rafaeli \& Pratt 1993: 38). Conspicuousness may vary from high to low, and prefaces the extent to which the women are identifiable by the job that they do, or meant to be doing while wearing the particular dress.

To explore how the women saw themselves, and how they saw themselves seen by others, I again approached the initial stance of the study, asking why the women chose to come to work 'dressed up' only to change into the uniform a few minutes later. As the narratives below reveal, in as much as the women wore the dress, it was also a case of the dress wearing the women.

Forty-seven year-old Lily*, a married grandmother with one daughter and three grandchildren, had to use two taxis to get to work from her home in Umlazi. Lily looked astonished that it was even conceivable that one would consider wearing the uniform from home, or even straight from work back onto the taxi. Her answers were unhesitatingly, "no" and "never" to the question of whether she might consider coming dressed for work in her uniform. Thirty-four year-old Zulu-speaking Dorothy* from Lamontville, an unmarried mother of three, was even more forthright in her answer, telling me she would never consider leaving the house in the morning in her uniform because "people would laugh at her", and that she "could not do this" because "it made her look old". Nomsa*, forty-eight, echoed these sentiments confirming what all the respondents answered to the same question asked in difficult ways, viz that they would "never" come to work dressed in the uniform as it was "too ugly". She added an idea shared by more than two thirds of the participants, viz. saying that the headscarf they were forced to wear as part of the uniform outfit, made her feel "like an old woman". Thirty-eight year-old Jabu*, mother of two teenage children, explained to me that, "No! No! They would laugh at me because it is too ugly". All of these women spoke to me alone and thus there was no opportunity for them to mimic each other's responses.

All the women mentioned that they felt that "everyone saw" them as cleaners and far from being invisible, they were highly conspicuous. Beauty*, a single thirty-year-old mother of two, added that even though everyone saw her in her blue dress, she still "felt like a nobody" wearing it. "So why must I wear it from my home?" She claimed that even though it was difficult to "wake up very early" and "take a taxi and a bus", to get to the University, she would, "No ... no ... not ever wear the uniform from home" as everybody would know that she was "working as a cleaner". She laughingly replied to the question of whether she thought men asked women in cleaner uniforms for dates, by saying "No, we look too old for them". She added that even if her boyfriend (hypothetically) were to visit her at work, she would "run to change into her nice clothes". All the women said that they arose fairly early to travel from their respective homes, in most instances using one, sometimes two modes of crowded public transport. Some mentioned that they had to "clean and make food", before coming to work. However, all were exceedingly skeptical of the suggestion that they might come for work dressed in the uniform in order to save time. The hidden subtext was also of course that when they arrived at work, only minutes later they would change into that same uniform.

The experiential import of the uniform as being "too ugly" or "really not very nice", as a few other participants phrased their response, was a sustained refrain in both the personal one-on-one encounters as well as during the focus groups. Many other women exclaimed that "you don't look nice' or 'it is not nice". Forty-four year-old Xhosa-speaking single mother, Princess*, originally from the Eastern Cape and now living in Kwa-Mashu, confided that she was "sick and tired of it" and it was clear that she would never entertain the idea of wearing the uniform for any time longer than was absolutely necessary, or outside of where it was absolutely necessary. Others were not coy in sharing that "you don't look nice" and their initial responses were all fairly revealing with their strongly articulated "No! No!" Clothing is instrumental in representing one's identity to others and acts as a kind of visual metaphor of identity (Droogsma 2007:296). While, for the cleaners, this seemed far from a desirable state of being (identified), it seemed that for obvious reasons it was tolerated within the context of organisational work, but not beyond.

Another woman, Gladys*, claimed that the uniform was dirty and "full of germs" and she "could not wear it" to her home. However, further gentle probing revealed that she wore the same uniform the next day and that with just one set of two uniforms, practical constraints meant she was unable to wash the dresses daily. The notion of 'dirty germs' must thus be refracted through other complex perceptions about the uniform which was deemed by mere necessity to be okay_and wearable at work, but not to be worn outside the work parameters. Upon further probing Gladys* revealed 
that she was not overly bothered about 'the germs', but sighed that the "uniform does not look nice".

Clearly, the women all understood that the practical exegetics of their work demanded that they needed clothing that they could actually work in, and possibly even risk soiling. In listening to them describe what they did wear to work and why they experienced the uniform as being ugly, it became clear that their notions of 'not nice' and 'ugly' went well beyond the material aesthetic, and was deeply entangled with what the uniform signified, which was experienced as almost a bodily tattoo once they put it on.

For when the women were asked to describe, and in some instances playfully draw on paper the kind of uniforms they would prefer wearing if they were obliged to wear any kind of uniform, their designs were creative and colourful and seemed to be aware of the specificities of their particular body shapes and sizes. In the conversations many workers bemoaned the fact that the uniforms were either "too long", or a "bit tight", or "old looking". All were in concert that in the summer they felt "too hot in them". The women also pointed out that they were only given a new set of uniforms every four years. When queried about what happened if they gained or lost substantial weight, Barto* exclaimed "they [the cleaning company] think that's our problem".

To probe the notion of 'styling' further (Huisman \& Hondagneu-Sotelo 2005), I asked the group of twelve women with whom I had had more sustained meetings, to draw what they would like their uniforms to look like. While initially shy, they warmed to the idea and began to giggle and enjoy themselves. This revisit of the earlier 'drawing exercise' allowed me to obtain a visual understanding of how the women wished to articulate themselves in a uniform, if uniforms were deemed requisite. Like the other earlier casual drawings, these sketches also seemed mindful of the drawer's body type and shape. I was also able to observe a clutch of nuances and cues that had initially escaped me. None of the drawings included a headscarf, nor did any of the dresses reveal buttons down the centre, or trimming around the apron. There were almost no design remnants of the original uniform in the women's sketches. By the same token there was an awareness that these dresses had to be practical and allow for movement and work. Pockets were added to the sketches and in cases where the women drew matching shoes (with little buckle detail) for their outfits, these were flat and sturdy. There were no allusions of impractical designs depicting flowing skirts, elaborate collars, or impractical working shoes. Two women added a jersey and three others gave me their idea of a summer work uniform. The women created practical work dresses that nevertheless reflected their own idiosyncratic preferences for different necklines, colours textures and simple patterns. While most designs did include a work apron, these appeared to be 'designed' to complement the dresses. Most importantly the dresses allowed the women to look different from one another. Barto* told me while holding up her sketch, "we know it must be a uniform, but they should make it a little bit pretty". She went on to say, "I'm not young, but I am not old ... this [pointing to her uniform] makes me look old ..."

\section{Creating homogenous bodies}

Although none of the women spoke directly about looking alike in the identical uniforms, it is perhaps a plausible assumption that there was a degree of awareness of this point contained in their subtextual references of being highly visible to staff, students and their immediate supervisors at work. In many instances, they responded by stating "we are seen as cleaners" far more frequently than in the singular of "I can be seen as a cleaner", indicating on some level, an awareness of (collective) dress homogeneity. This was the primary rationale behind them not wanting to wear the uniform on the taxi's and buses.

The precise concerns about cleaning work the women voiced were still opaque and hidden behind their response of the uniform being "too ugly" or "dirty". One way of attempting to unravel their responses was to ask what other kinds of work they thought they would enjoy doing. The women seemed eager to share their preferences which appeared to (fleetingly) reflect something of their social selves beyond that of being a cleaner. Although none of the alternative "jobs" they mentioned seemed overly ambitious, they were nonetheless inspired to provide their ideas and it was moving to hear them speak about "what they liked". Futhi* commented that "you have to get on your hands and knees to clean ... I want to work like my friend and make the tea for the lecturers". Others referred to women who worked as "messengers", carrying university mail to various departments and thought that was "good work". They responded frankly and eagerly that they liked to "do sewing work" or "dress-making". A few of them spoke about their passion for "hair-styling". While the women mentioned that they wanted wellpaying work, it was revealing that the "jobs" they mentioned did not require the use of a uniform as such. When I asked how they felt about the fact that office and lecture spaces could be occupied largely because of their efforts to keep these spaces clean, Gladys* shrugged her shoulders and said, "yes but it gets dirty again and we must clean again". Many other women shared this sense that their work was repetitive and that they maintained spaces that were just going to get dirty again. Some of the women did eventually confess despondently that they went home and had to "cook and clean again". This may cautiously suggest as being part of the rationale behind why they did not want to be associated with cleaning work, and having to wear the (homogenous) uniform on public buses and in taxis. It did not seem like the women were by any means 'thrilled' that their cleaning labour facilitated the functioning of learning and work spaces. Instead, it appeared almost as if they saw little value in the kind of work they were doing, and on some level they were voicing exasperation with the repetitiveness of it. Uniforms have dress attributes that are potentially able to reveal someone's social status which Rafaeli and Pratt (1993; 1997) refer to as 'cues'. The cues that the women appeared to be reacting to seemed to be the association with the repetitive cleaning work.

Winter, arriving a few months after the initial period of interviews, allowed a renewed context of participant observation. The women now had to dress appropriately against the cold weather. I was keen to observe how, if at all, the visual homogeneity was being preserved by the cleaning company. The women however, were seen wearing differently 
styled jerseys over their uniforms, and commented that the "company" did not "give" or fit them out with jerseys or jackets. Barto* pointed to her blue jersey and said that it was part of the uniform of a friend who was employed at a post office and that he had "given" it to her. She beckoned to a coworker through the window and said, "That one is wearing her son's school jersey". Mentioning to Nombusa* that the winter jerseys allowed some sense of individuality was rewarded with a pursed face and the reply that ".... they tell us we must make sure we get a jersey that is black or blue". When I attempted to labour the point that at least they could wear different jerseys, which made them look somewhat less identical, Nombusa* gave an incredulous look exclaiming that "you can still see the uniform underneath .... we don't look different ... we look funny ... sometimes we wear the children's school jerseys when they [the children] get big ... but the jersey maybe is not a good size for us".

I had sought out Nombusa for a specific reason. During the early interviews, she indicated that she did not mind the blue colour of the present uniform "too much". She had thought however, that perhaps the workers could have been given "different colour dresses" so that they could "look different ... sometimes". She continued to tell me that "when we walk together" everyone "can see cleaners walking" and that sometimes people tossed their "papers" into boxes or bins they were holding, or approached them with "the toilet is dirty" and "they must please come clean". "The people are not rude" she said, "lots of the students and lecturers say hello or good morning, some of them know our names ... but ... we still look like cleaners ... that's why they know us." The women's stories of how they experienced and felt about themselves in day-wear they chose for themselves in relation to how they experienced themselves in the prescribed uniforms, indicated that the uniform was experienced as making their bodies highly conspicuous as cleaning women.

Although not a formal part of the sample community, about I 20 staff and students across two campuses were surveyed in the latter stages of the research. This was mainly an attempt to situate the cleaners' experience of themselves as being regarded as cleaners alongside how others might see them. The responses by staff and students appeared to bear out the experience of the cleaners, for like the immediately recognisable docile bodied soldier of Foucault (1977), the uniform on the cleaner's body was immediately associated with cleaning work, and the women as cleaners. Most of the respondents appeared surprised that I was asking such obvious questions, the meaning being that it was self-evident that these women were cleaners. The uniform also appeared to "divide" (Foucault 1982: 777) cleaners from non-cleaners and by so doing, further worked to demarcate hierarchies of power relations. This is also expressed in how the women's supervisor was demarcated from the cleaners, who the cleaners said, was "allowed to wear her own clothes".

Rafaeli and Pratt (1993: 45) claim that dress homogeneity has 'deindividuation' effects. And on a certain level the visible homogeneity of dress or uniform appears to undergird a kind of homogeneity of existence (Bourdieu 1977). The uniform acts to objectify and construct a particular group habitus with a set of durable dispositions and induced proclivities to behave and inhabit the work space in a particular way, as cleaning women. For Bourdieu, habitus is a system of internalised cognitive and motivating structures themselves produced by the structures of a particular social (in this case organisational) environment. These structures of environment lead to behaviours that are in turn re-produced through the generativity of habitus (Bourdieu 1977: 78; 1990: 53).

Dispositions are said to be inevitably reflective of the social context in which they were acquired. The highly conspicuous dress of the cleaners' uniform acquired in an organisational context can be predicted as demanding and 'inspiring' greater compliance, experienced as a kind of dress-consciousness, because it is clearly distinct from what individuals might select to wear (as the women's drawings showed). This serves to further congeal the sense of the women's job as cleaners and how they should feel, behave and move around as cleaners in the University, thereby working to reinforce the habitus.

The experience of uniform-dress also works to efface the materiality of the body as social self beyond the inscribed parameter of cleaner, revealing that the cleaners' bodies are experienced within particular constructed social contexts. From what the women communicated, wearing a jersey did not cover the conspicuousness of the uniform, and they still experienced themselves as "looking the same", and "feeling the same". For the cleaners working at the University, the experienced conspicuousness of the uniform can be seen as upsetting other experiences of body (and self-) perception, and about other perceived skills about themselves such as hairstyling or dressing-making. The import of the uniform is thus very much experiential and beyond "mere verbal discourse" (Bourdieu 1977: 120).

\section{Dressing the body beautiful}

Colours (of dress) may bear valuable symbolic information, and research in various modes of nonverbal communication appears to suggest that there are embedded communicable meanings in different colours. Blue is supposed to convey dignity, and red passion in certain cultures. However, comments from the women revealed that this did not apply to them. The women I spoke to preferred "happy" and "brighter" colours and did not experience any degree of dignity associated with blue. Nombusa* said that she would like her uniform to be a "yellow-sunshine colour". While some women said that "blue was ... okay", others said they thought it was "too dark", and compared it to the brighter colours they would normally choose to wear. Initial informal observations showed that even though the dresses that the women wore to work were not extravagant, they were nonetheless colourful and styleful.

Prompted by the suggestions of a reader of an early draft of the paper, I routinely observed the dress preferences of the cleaning women at the Howard College campus. The women were observed over a period of three weeks as they arrived by public transport and as they left again for home in the afternoon. Two different arrival points at different ends of the campus were identified, and I moved between them. The women observed at the arrival point were only in some cases, the same women who had been interviewed. As the period of observation was mid-August to mid-September, the days were punctuated by sunny yet cold temperatures, very 
much the norm for Durban. Notwithstanding the cold mornings, none of the women observed chose to cover their heads with a headscarf as protection against the cold. A few women wore beret style woolen hats while most chose to go bareheaded. Although the women wore heavy coats or jerseys against the cold, the bright colour of their casual dresses was clearly visible, as were in certain instances their moderately made up faces. The women interviewed commented that they felt attractive in their own clothes and enjoyed using perfumes, and many added that they liked to use lipstick. Princess* added that her "pretty pink lipstick" did not look as good when she "put on the uniform".

All the women told me that they went through the routine of dressing up again before taking their buses and taxis home. Many of them appeared to share lockers. Their personal belongings, clothing and cosmetics could be seen to be carefully stored here. Here too they would put on the "perfumes", alluding to the aerosol colognes, and "some lipstick", before leaving for home. Barto* showed me where she had propped her piece of mirror and Princess* pulled a little purse mirror from her handbag. Neither of them bothered to look in the mirror during the course of the work day in the way that other women might do. The mirrors were used only when they looked to blot out traces of tell-tale lipstick before commencing work, and when they put on the lipstick to complete the dressing up routine. It was not seen as fulfilling any particular "technique of body management" (Lewis 2007) to be bothered with their appearance while in uniform, in the same way as they might fix their hair or face while wearing their personal items of clothing.

The women appeared to experience the process of dressing up for and after work less as a ritualised process than as a habitual process. From what I was able to observe, this took no more than a few minutes to accomplish. What was interesting to observe were the nuanced differences in their demeanour after they had changed out of their uniforms. This difference appeared to articulate itself in the body hexis of the cleaners. Body hexis is, in a way, the performative aspect of habitus when the body is endowed with a clutch of social meanings and values (Bourdieu 1977; 1990). Prompted, in part of course, by the particular bodily techniques demanded by wearing higher heeled shoes, a bag over the shoulder, or a flowing skirt, they seemed to possess their bodies more completely. While this may well appear to render their bodily behaviour unjustly esoteric, or suspiciously impressionistic on my part, their communication with me does appear to bear out this observation.

Although initially self-consciously aware that I would see them after they had changed out of their uniforms, later in the research they seemed to grow accustomed to me "hanging around'. When asked if they felt different soon after changing, most women unhesitating said "Yes, it's nice to wear my clothes". One woman looked down at her dress and said "It's old but nice and my daughter bought it for me ... it makes me look and feel nice." A few women did not seem to understand what I meant by "feel different", although they commented that they could not wear their "nice" earrings or "anything pretty like that with the uniform". When asked why they "just did not change at home" forty-four year old grandmother of four, Lindiwe* from Ntzuma was forthright and said that she felt "pretty in my own clothes", but that she felt "like an aunty in the uniform". She added, "People will laugh if I wear the uniform. I don't want people to see me in the uniform." She then commented, "Hey, I don't want to see the uniform too much".

When I asked Pretty* why she did not wear a scarf on her head since it was winter, she gave me a withering look and said "Scarf is for the uniform ... not my dress". Many of the other women subsequently shared that while they wore headscarves at home over the weekends, they chose not to wear them as part of their casual dress when traveling to work because of the inherent association with the uniform. It appeared that the bright green headscarf completing the dark blue uniform had been co-opted with the apron worn over the uniform. Here it appeared that the scarf was not viewed as something bright and pretty, but rather brightly conspicuous. Just as one would not wear an apron, except for functional reasons, so too the women were appearing to refuse using a head scarf because for them, the scarf on the head was so closely allied with the uniform and the cleaning work that went along with it.

Clothing and appearance generally, firmly embedded as they are within social and cultural contexts, exert social control, particularly in the lives of women according to Droogsma (2007: 296). It may well be that the women are confronted with other social conscriptions in the 'kinds' and 'quality' of the self-selected clothing they were wearing. This may in turn place them in other discourses as social selves constrained within particular cultural and socio-economic fields. The point is however, that at the very least, the "dividing practice" (Foucault 1980) visually embedded in the uniform and demarcating the cleaners from all those who were not, was at least discarded when they were wearing clothing they had selected. More importantly, so was the particular "relation of docility-utility" (Foucault 1977: 137) that the uniform claimed.

While the women may be less confrontational with the disciplining inscription of their own clothing, they were not unaware of the value of choice within the constraint of context as they sought to stay clear of particular kinds of inscribing clothing, such as head-scarves and pinafore- type dresses reminiscent of the work-apron. According to Ruitenburg (2008: 22), the act of wearing, or refraining from wearing, particular objects of clothing is both an expression or representation of a pre-existing subjectivity and of social identity, as well as participation in the repetition of the very signs that produce subjectivity and social identity.

\section{Claiming ownership and proprietary rights}

While the uniform itself may appear to be a mere mundane materiality, it acts to inscriptively render "bodies passive" (Lock 2007) in the work context through routine and repetitive legitimation and in a literal sense, uniformity. Judith Butler (1988: 524) draws on the work of Victor Turner whose studies of ritual social drama reveal that social action requires a repetitive performance. This repetition is simultaneously a "re-enactment and re-experiencing of a set of meanings already socially established", even as it comes to be played out as a "mundane and ritualized form of their legitimation". Discreetly observing the women emerge from the staff 
rooms immediately after changing into the uniform prompts a suggestion that the repetitive donning of the uniform was a bodily 'ritual' but in a very mundane sense. It would be more accurate to speak of it as a habitual routinised performance, and not something that the women consciously thought about as they moved from one kind of dress to another. A few of the women did indicate, after I probed gently, that they were "used to changing" and declared that "it did not take too long". One woman, Jabu* said, perhaps insightfully about when she changed out of her own clothes, and her coworker nodded in agreement, "Now I know I must work". While this may be no more significant that the average worker clocking in thereby reminding her that she has begun her work day, Jabu's* subsequent comment that "the supervisor also knows that now we must be working", was more revealing. The uniform's purpose here was seemingly to 'tip off' to Jabu that she (and her labour) could now be seen and monitored.

Judith Butler's thesis $(1990 ; 1993)$ is that there is no such thing as a pre-inscriptive body, and argues that bodies have always already been interpreted by cultural meanings. It is not to suggest that the uniform applies a particular script onto a natural(ly occurring) body. It is recognised that multiple gender, ethnic, sexual and other scripts cohere in varying degrees of congruity and incongruity in the cleaner's bodies, each exercising particular modes of persuasion and coercion to perform and enact culturally encoded behaviours. What is suggested and borne out by the narrative 'texts' shared by the women is that the uniform can also be seen as a particular kind of inscription that etches and plays itself out through the site of the body.

Bodies emerge as being 'owned bodies' (Butts 2007: 62), and proprietary rights are enacted through inscription that plastically mold and shape perception, and thus also, appropriate behaviour. The women were often apprehensive about being confronted by their supervisors for not working, (i.e. not cleaning) even though they were talking to me during their lunch breaks, a portion of time that was legitimately their own to do with as they pleased. In part, because they were wearing a (work) coded garment, they experienced themselves as being under the proprietary control of their respective supervisors, despite the lunch breaks.

The uniform was experienced as a script of (inherent powerful) persuasion. In contrast there was an absence of a sense of urgency and a fear of being spotted when the women spoke to me when dressed in their casual wear. It may be pointed out that the women were understandably more relaxed as the work day was over and this was their time. However, the lunch breaks were also times that belonged to the women and not the 'job'. Yet they were often 'on edge' and fearful that the "supervisor would come" and "see" them "not working". From this behaviour it was evident (frequently with the same participant during follow-up meetings) that the meaning of the uniform had been interiorised (Foucault 1980) and acted to 'hold' the women in surveillance. Thus even though it was their legitimate lunch break, the women were conditioned into either having to work, or breaking for lunch so that any 'event' outside of those two highly routinised acts were cause for concern and that they would be perceived as not working. Reminded by the sight of the uniform and represented by the authority manifest in the figure of their supervisor, the women could not help feeling as if they were 'owned by the work'.

Grosz's (1987) concept of 'plasticity' evidences that the body is there to be molded, and is capable of being formed and organised. The malleable body canvas is understood as being vulnerable to manipulation through the disciplinary exercise of power. The notion of 'plasticity of body' in the context of the cleaning women allows an understanding that the material exercise of power operates through an inscription of the norms and disciplinary injunctions of the employer on the body. The body is not an inert substantial material, but is plastic and susceptible to alteration (Barker 1998: 21).

Nombusa* told me in the earlier interviews that she especially despised having to wear the old-fashioned headscarf like "those maids". When asked why she did not want to look like a domestic worker, she claimed that she did not like "working as a maid", because when she was in such employment, she was "watched closely" as the "madam was around the whole day". While some of the women had worked as domestic workers and had claimed to have enjoyed this work, it emerged that most of them had worked in homes where the employers were themselves employed and absent for the day. A few other cleaners who had worked in households where the wife was present throughout the day, felt that working as a cleaner was preferable to being a domestic worker. Many women appeared to voice that they wanted to just get on with their work and not be monitored or chaperoned. It seemed that the uniform was a reminder that they should be working. It was not so much that the women were objecting to having to work, just that they needed the reminder to do so.

The discursive concept of ownership and the practice, or exercise of, control and proprietary sentiments are deeply intertwined. Ownership therefore, is a discursive framework allowing a probing of interactions in which an element of control is present (Butts 2007: 63). The women appear to be examples of the objectivised and owned subject by what Foucault (1982: 777) refers to as "dividing practices", where the women come to be divided from the others who are not cleaners.

The body is plastically acted upon, inscribed in this context with perceived organisationally correct behavioural codes. To borrow from Pippa Brush (1998: 37), the constitution of the body comes to rest "in its inscription", and for the women, the codes inscribing them as cleaning women constitute their bodies and how they experience their selves and their bodies as having to be engaged in work. Some of the women alluded to the fact that they felt that they had to be constantly engaging in some kind of designated cleaning activity. Rafaeli and Pratt (1993) argue that organisational dress affects the workers' compliance with the standards of behaviour inherent in their role. They claim that often the dress or uniform is proposed also to affect the extent to which employees fulfill the necessary worker or role requirements. They go on to refer to their study and assert that workers "who wear organizationally designated attire are psychologically in a position of having complied with greater organizational standard" than employees who wear their own chosen or "self-selected" clothing (Rafaeli \& Pratt 1993: 44). Cer- 
tainly the women can be observed, as they interacted with each other (and even with me in subsequent meetings) of being oblivious to being in uniforms. However, there were enough hegemonic cues embedded in the uniform for them to be readily reminded, either by their own self-inspecting gaze or that of another, that they were cleaners.

\section{The bodily enactments in space}

Lewis (2007) refers to dress as an embodied practice, which is also very much a practice that is spatialised and temporal. She presses the point that the dressed bodies are given meaning through their location in specific times and places which have their own rules of dress and comportment. Certainly the women attempt to enter the offices surreptiously, and can be observed to tiptoe around the academics working in their offices. They claim that they feel that, as cleaners, they "must not trouble the lecturer", and "must get the job done quickly." Quite often, as Pretty* described, they need to clean around the academic who is poured over the monitor, email, or paper documents etc. Wearing a uniform of any sort seems necessarily to imply mastering "particular techniques of body management" (Lewis 2007: 427). The homogenously dressed and uniformed women can thus be seen as moving through multiple spaces inhabited by heterogeneously dressed bodies.

Space is claimed as not being an inert entity in which things just happen. Massey's critique of space is that it is dynamic, and the different places that dressed bodies inhabit are relational, acquiring distinction and meaning from their relationship to what lies outside the coordinates of that space (Massey 1994). At a very literal level the women inhabit and move their bodies in various ways through differently experienced demarcated coordinates of space. They are comfortable when they are with fellow co-workers in their staff room, but feel that "they must work quietly in the lecturers' offices". Women like Jabu* and Futhi* mentioned that the lecturers are "nice" and "some ask how we are, they know our names ... but after we say good morning ... we start working ... we don't talk too much."

Futhi* described how she negotiated moving through various spatial realms. Speaking to me for the second time, she commented that she was "always scared" that she would accidentally trip the electrical plug while the academic was working. Since this had once happened to her and a coworker, she worked cautiously in the offices. Princess* felt comfortable enough in our third meeting to confide that she always worried that she would drop something of mine, the 'mine' being all the "things" as Princess* puts it, in my office. This referred to my prized African art, and several equally coveted Buddha heads brought from a Nepali adventure. Her (self-confessed) praxis clearly revealed her variously articulated body movements through different 'spatial regimes' with varying degrees of self or body consciousness. Such movements show that the cleaners belong to more than one 'spatial community', and that they engage with 'overlapping sets of spatial relations whose socialising effects' produce differences that they constantly negotiate. The cleaners appeared to negotiate different 'spatially realized' sets of hegemonic norms, produced by specific (organisational) 'constellations of power' and which vary in terms of 'formality, enforcement and stability' (Lewis 2007: 427). Lewis claims that these regimes of space include the normatisation of behaviour while inhabiting them (2007: 427).

\section{Disciplining: a source of resistance?}

I have largely presented the uniform as a means through which particular disciplining of the women's body is exercised and experienced. It may be pointed out that the disciplining of the body may be used as a source for an opportunity for resistance. Foucault himself described power as a series of strategic relations and asserted that relations of power also offer the possibility of resistance (Foucault 1980: 142). However, the ethnographic observations do not endure the evidence of this sort of resistance, whilst in the uniform anyway. The cleaners, in all conversations and observations, showed no indication of offering material resistance to how they were obliged to dress for work when they were in the work space and during the formal working hours. While one confesses that it does appear a rather stark bifurcation of uniform as illustrating discipline and self-selected clothing as illustrating agency, the ethnography in a sense does bear this out. Of course the women, as part of the larger cohort of contracted workers, were not passive. They had opinions, attended meetings and attempted to resist and contest what they felt management was doing to them as workers who deserved a better wage. However, they were not intent on resisting other levels or modes of subjection directly with management. When asked why they did not collectively ask for uniforms that were more to their liking, or just raise issues about the uniform in general, most laughed that it was more important that they were paid properly. While it is a legitimate assertion that the uniform is a means by which the women are turned into subjects, it is understandable perhaps, that the women themselves had hierachied the issues cohering around the uniform as being substantially less important than the pressing issues of their poorly salaried labour.

According to Lewis (2007: 427), wearing a uniform of any sort seems necessarily to imply the mastering of 'particular techniques of body management'. Huisman and HondagneuSotelo (2005: 47) assert that, for the marginalised or subordinated groups, self-chosen dress also takes on important meanings for individual and collective identities. Huisman and Hondagneu-Sotelo's study showed that subordinated groups often use the agentive choice of dress to transcend their position in systems of inequality. They claim that the practice of 'styling' allows people, who in many instances are at the mercy of other peoples' definition, to exercise power over how they are seen and how they are defined. Messing (1998: 178) also gives an example from her study of how the cleaners in a hospital evolved strategies to cope with issues of invisibility and lack of respect. She repeats the anecdote of one of her participants who claimed to always dress in stockings and heels (alongside her uniform), despite the difficulties involved in fulfilling some aspects of her cleaning tasks whilst in heels.

However, observations of the University cleaners revealed no similar 'styling' or strategies of resistance when they were dressed in the uniforms. The responses of the women as well as observations of them suggest that there is no discernable agentive self that seek to change how the uni- 
form is worn at work. Dogged by fears of job security and pressing financial needs of their families, they offered no resistance to their dress within the work space. Barto* confided in me that her female (black African) supervisor insisted that they remove their earrings and any other jewelry and even asked that traces of lipstick be removed. Such "meticulous control" over bodily practices imposes a "relation of docility-utility" (Foucault 1977: 137) on the cleaners. And even though Barto* and the others would have favoured wearing their earrings since they did not interfere with their work, as rings on a finger might have, they deferred to the instructions. When I enquired from Barto* why she thought this was so, Barto*, in a manner I had grown to appreciate as her personal brand of frankness exclaimed, "She is jealous ... only she must look nice". Although the women agreed that their supervisor was "alright", they all resented her being overly strict with them.

The cleaners also did not resist the uniform at work by attempting to introduce elements such as colour, even in the jersey, which was the one item of clothing where there was a measure of discretionary 'choice'. Nor did they, like the cleaner in Messing's study, opt to turn up for work wearing heels or stockings under the uniform. I did notice that Princess* continued wearing her gold coloured hoop earrings. However, her laughing answers revealed that it was less a matter of offering resistance than an attempt to sneak around what she saw as a 'rule' in the same manner that a little school girl might. The reason why I hesitated to read this as even a modest attempt at 'resistance' was simply because she did not intend it as such. She had replied candidly that if asked to, she would simply remove the 'offending' piece of jewelry.

\section{Conclusion: Attempting to claim back}

The (visible) uniform appears to make it acceptable for the supervisor to ask and the women to concede to items of jewelry and make-up, such as the seemingly innocent lipstick, to be removed. The highly conspicuous uniform as a mode of disciplinary coercion thus allowed 'appropriate' behaviour to be plastically molded onto disciplined and docile bodied cleaners. The disciplined body is also one from which power has been dissociated (Foucault 1977). States Foucault.

In discipline, it is the subjects who have to be seen. Their visibility assures the hold of power that is exercised over them. It is the fact of being completely seen, of being able always to be seen, that maintains the disciplined individual in his subjection (Foucault 1977: 187).

The hold of power, I argue, is exercised through the visibility of the panoptic uniform, to the women and to observers. It forces the women to be "completely seen", to the extent of being (non-materially) coerced into having "interiorized" (Foucault 1980) and seeing themselves as cleaners, even during their supposedly free lunch times, in their cleaner uniforms. While I may be mistaken for a rather senior student, or as a secretary heading to her office, the cleaners, as those who are "always seen" cannot be mistaken for anyone else. This 'always being seen' in turn, elicits compliant behaviour deemed appropriate by the supervisor.

However, 'power' as a series of strategic relations (Foucault 1980), is in no one particular place but 'every- where', and if not in one space, offers the possibility of resistance in another. The cleaners' resistances may be discerned rather in the context of the self-selected clothing and their revealed answers about emphatically not wanting to 'ever' wear the uniform out of working hours, and outside the spatial domain of the work space. There is a subtle but critical point of difference here. It is not that agency was displayed in wearing self-selected clothing (because in the first instance, they were not wearing it at work) but rather an agentive self is revealed in them choosing emphatically not to wear the uniform outside the University space. They had resolutely refused to consider the 'benefit' of time, effort and energy that could possibly have been gained from coming to work already dressed in the work uniform.

The women appeared aware of the subjectivising effect of the uniform in their narratives of sustained response of not wearing the uniform outside the domain of the University. The uniform subjectified the women into being highly visible, conspicuous, and thus plastically malleable to particular behaviours deemed acceptable for work. The uniform also disciplined the women into objects of surveillance by themselves and management at work. And lastly, the single-layered cleaners' uniform-dress worked against the women's aesthetic sense of being and feeling "pretty". The uniform acted instead to transcribe homogeneity and strip away the complex multi-layers of their personalities inside the work space, further reifying and naturalising their status as cleaners.

The cleaners to whom I spoke seemed aware that they 'felt' and 'experienced' themselves as somewhat different when not wearing the uniform, even if they did not possess an artillery of sophisticated vocabulary to describe this 'experiencing'. Even though they seemed 'powerless' to resist the disciplining and molding of the uniform or to act out any other articulation of self in the context of work, they appeared to take full advantage of the times before work commenced and at the end of the work day, to not wear the uniform. This is not to be understood as merely indexical of what to wear, or what not to wear in particular spaces. The women's responses were not merely conveying that the uniform should not be worn to or from work, but that they expressly did not wish to wear the uniform outside of work spaces, and that they wanted to 'feel' different.

It appeared from what they said, and more especially from how they appeared in their own clothing, almost as if they were attempting (within the constraint of the context in which they functioned) to destabilise the body hexis that had been performed at work. The women appeared to want to negate the subjectivising uniform in which they did not feel pretty or feminine. They also wanted to shed the embedded surveillance of the uniform that extracted 'docile-utility' from them by making them hypervisible. The interviews with the women show that they were fully aware that their uniform acted as a 'local mechanism of power', and suffered from an almost generic legibility or association with cleaning work. It appeared that they attempted to destabilise and weaken the plastic conscription of the body within the familiar trope of cleaner, outside the work context.

Of course, as they said, they all knew that they "were cleaners". However as Futhi* told me, "After work I want to put my T-shirt and skirt on and forget about cleaning for a lit- 
tle bit of time." There was thus an awareness of the discipline, but it occurred in that relatively short but significant window period before coming to and being subsumed by work, and when they completed the work day and dressed to return home. The women thus emerge as nodes in a web of relations as they simultaneously exercise some form of control and power over the physical body and self, even as they experience the effects of power over themselves. They attempt to retrieve their social selves beyond cleaners from the inscriptions layered on by the uniform that disciplines and places their bodies into a distinct social location. Power is not innately hierarchical so there is no single site of revolt (Barker 1998: 28), and it made sense that there was no one particular point of highly dramatic resistance on the part of the cleaners, but rather on-going and daily 'little' resistances, such as choosing not to wear the uniform to work, or not choosing, anything that remotely resembled the uniform as part of their self-selected ensemble.

\section{References}

Appadurai, Arjun. 1986. "The origins of Swadeshi (home industry): Cloth and Indian society, I700-1930". In The social life of things. Edited by Arjun Appadurai. Cambridge: Cambridge University Press.

Barker, Philip. 1998. Michel Foucault: An introduction. Edinburgh University Press: Edinburgh.

Bourdieu, Pierre. 1977. Outline of a theory of practice. (Trans. Richard Nice). Cambridge: University Press.

Bourdieu, Pierre. 1990. The logic of practice. Cambridge: Polity Press.

Bordo, Susan. 1993. Unbearable weight: Feminism, western culture, and the body. Berkeley, Los Angeles and London: University of California Press.

Brush, Pippa. 1998. Metaphors of inscription: Discipline, plasticity and the rhetoric of choice. Feminist Review 58: 22-43.

Butts Angela. 2007. "Signed, sealed, delivered ... I'm yours" Calibrating body ownership through the consensual mastery/ slavery. Dynamic Sex Cult I I: 62-76.

Butler, Judith. 1988. Performative acts and gender constitution: An essay in phenomenology and feminist theory. Theatre Journal 40 (4): 5|9-53।.

Butler, Judith. 1990. Gender trouble: Feminism and the subversion of identity. New York: Routledge.
Butler, Judith. 1993. Bodies that matter: On the discursive limits of sex. New York: Routledge.

Connell, Robert W. 1994. Bodies and genders. Agenda 23: 7-I8.

Droogsma, Rachel Anderson. 2007. Redefining hijab: American Muslim women's standpoints on veiling." Journal of Applied Communication Research. 35, 3, pp. 294-319.

Durham, Deborah. 1999. The predicament of dress: Polyvalency and the ironies of cultural identity. American Ethnologist 26 (2): 389-4II.

Foucault, Michel. 1977. Discipline and punishment. (Trans. A Sheridan.) New York: Random House. $2^{\text {nd }}$ Edition.

Foucault, Michel. 1980. Power/knowledge. Edited by Colin Gordon. New York: Pantheon Books.

Foucault, Michel. 1982. The subject and power. Critical Inquiry 8 (4): 777-795. http://www.jstor.org/stable/I343/97 Accessed: 25/08/2009 06:36.

Foucault, Michel. 2006. "The body of the condemned". In Anthropology in theory: Issues in Epistemology. Edited by Henrietta Moore and Todd Sanders. USA: Blackwell Publishing.

Grant, Brenda. 1997. Domestic workers: Employees or servants? Agenda 35: 61-65.

Grosz, Elizabeth. 1987. Notes towards a corporeal feminism. Australian Feminist Studies 5: I-17.

Huisman, Kimberly and Hondagneu-Sotelo, Pierrette. 2005. Dress matters: Change and continuity in the dress practices of Bosnian Muslim refugee. Women and Gender and Society 19 (I): 44-65.

Lan, Pei-Chia. 2003. Maid or madam? Filipina migrant workers and the continuity of domestic. Labor Gender \& Society 17 (2) 187 208.

Lewis, Reina. 2007. Veils and sales: Muslims and the spaces of postcolonial fashion. Retail Fashion Theory II (4): 423-442.

Lock, Margaret. 2007. "Beyond the body proper: Reading the anthropology of material life", in Body, commodity, text. Edited by Lock, Margaret and Judith Farquhar. Duke University Press: USA.

Massey, Doreen. 1994. Space, place and gender. Cambridge: Polity Press.

Messing, Karen. 1998. Hospital trash: Cleaners speak of their role in disease prevention. Medical Anthropology Quarterly. 12:168-187.

Rafaeli, Anat and Pratt, Michael G. 1993. Tailored meanings: On the meaning and impact of organizational dress. Academy of Management Review. 18 (1): 32-55.

Rafaeli, Anat and Pratt, Michael G. 1997. Organizational dress as a symbol of multilayered social identities. The Academy of Management Journal. 40 (4): 862-898. 